\title{
Filosofia da ciência e evolução: uma contribuição ao ensino Parte 1: Por que ciência?
}

\author{
Francisco José de Figueiredo \\ Doutor em Ciências Biológicas (UFRJ), Professor Associado do Departamento de Zoologia (UERJ) \\ $\triangle$ fjfig@globo.com \\ Levy Aquino de Oliveira \\ Graduando em Ciências Biológicas (UERJ), Monitor da disciplina de Evolução do curso de graduação \\ em Ciências Biológicas (UERJ) \\ $\square$ levyaquino2009@hotmail.com
}

Recebido em 6 de junho de 2020

Aceito em 26 de julho de 2020

\section{Resumo:}

Evolução é um conceito-chave para o ensino das Ciências Biológicas, tendo em vista que integra áreas diversas dentro da ideia de relações históricas entre organismos e seus atributos por causas naturais. Porém, tem sido negligenciada ou omitida em salas de aula por várias razões. Uma delas é a falta de treinamento básico de professores do ensino médio em Filosofia da Ciência. Consequentemente, nesses "tempos líquidos", alunos têm ingressado nas universidades mostrando deficiência na compreensão e assimilação de conceitos científicos básicos, não distinguindo ciência de outras formas do saber. Atualmente o conhecimento é acessível a todos, principalmente na internet. Porém, aquele que melhor condiz com a realidade tornou-se muito restrito e modular. Nesse hiato, pseudociências têm ocupado lugar de destaque entre ciência e religião, usando jargão científico, mas imunizando evidências contrárias, banindo validação externa, investindo em evidências negativas e adotando explicações ad hoc. Ao contrário desse tipo de abordagem, ciência oferece métodos de analise rigorosos nos quais o ceticismo é aplicado na investigação de argumentos e fatos. Em sociedades cuja disfunção social é evidente e aguda, a noção de realidade tende a ser substituída por fantasia ou alienação e, com isso, há proliferação de todo tipo de informação sem base racional. Diante disso, conceitos da Filosofia da Ciência e ferramentas do método científico constituem eficazes recursos na avaliação de ideias correntes numa sociedade que preza pela liberdade de pensamento e expressão. Saber quais são essas ferramentas é fundamental para o entendimento e avaliação de aplicações e implicações da teoria evolutiva.

Palavras-chave: Evolução, Filosofia da Ciência, Método científico, Ensino de Biologia.

\section{Philosophy of science and evolution: a contribution to the science teaching Part 1: Why science?}

\begin{abstract}
:
Evolution is a key-concept for teaching biological sciences because it joins different branches from biological sciences within an idea of historical relationships between organism and their attributes by natural causes. However, it has been neglected in classrooms for several reasons. One of them is the lack of training of high-school teachers in the Philosophy of Science. As a result, in these "liquid times", students have enter universities demonstrating reluctance regarding comprehension and assimilation to scientific concepts, since they do not distinguish sciences of rival ways of knowing. Nowadays, different ways of knowing are accessible for all people, mainly by internet web. However, those more reliable became restricted and modular. In this gap pseudosciences have invade and occupying place between science and religion, using scientific language, but immunizing contrary evidences, banishing external validation, investing on negative evidences, and applying ad hoc hypotheses. In this way, pseudosciences stand up as linking between sciences and religion, using
\end{abstract}


scientific discourse, but immunizing contrary evidences, constraining external validation and investing in negative evidences and hypotheses ad hoc. Against this approach, sciences offer rigorous analytical methods in which criticism and skepticism are used on the evaluation of facts and claims. In societies whose social disfunction is clear and sharp, objective reality trends to be change by nonsense, favoring dissemination of all forms of non-rational arguments. In this, concepts from philosophy of science and tools of scientific methodology are useful in the evaluation of ideas in those societies committed with the freedom of thinking and expression. These tools are essential for understanding and to evaluate applications and implications of the theory of Evolution.

Keywords: Evolution, Philosophy of Science, Scientific method, Science teaching.

\title{
Filosofía de la ciencia y evolución: una contribución a la enseñanza de ciencias Parte 1: ¿Por qué la ciencia?
}

\begin{abstract}
Resumen:
La evolución es un concepto clave para la enseñanza de las ciencias biológicas ya que integra diferentes áreas dentro de la idea de las relaciones históricas entre los organismos y sus atributos debido a causas naturales. Sin embargo, se ha descuidado o pasado por alto en las aulas por varias razones. Una de ellas es la falta de formación básica de los profesores de la escuela secundaria en filosofía de la ciencia. Por consecuencia, en estos "tiempos liquidos", los estudiantes han ingresado a la universidad mostrando deficiencias en la comprensión y asimilación de conceptos científicos básicos, sin distinguir la ciencia de otras formas de conocimiento. Hoy en dia el conocimiento es accesible para todos, principalmente por internet, sin embargo, el que mejor se adapta a la realidad se ha vuelto muy restringido y modular. En este hiato, la pseudociencia ha ocupado un lugar desatcado entre la ciencia y la religión, utilizando jerga científica, pero inmunizando evidencia contraria, prohibiendo la validación externa, invirtiendo en evidencia negativa y adoptando explicaciones ad hoc. Por el contrario de este tipo de enfoque, la ciencia ofrece métodos rigurosos de análisis en los que se aplica el escepticismo en la investigación de argumentos y hechos. En sociedades cuya disfunción social es evidente y aguda, la noción de realidad tiende a ser reemplazada por fantasía o alienación y, con esto, la proliferación de todo tipo de información sin una base racional. Por lo tanto, los conceptos de la filosofía de ciencia y las herramientas del método científico constituyen recursos efectivos en la evaluación de las ideas actuales en una sociedad que valora la libertad de pensamiento y expresión. Saber cuáles son estas herramientas es fundamental para comprender y evaluar las aplicaciones y las implicaciones de la teoría evolutiva.
\end{abstract}

Palabras clave: Evolución, Filosofía de la Ciencia, Método científico, Enseñanza de Biología.

\section{INTRODUÇÃO}

De acordo com Mayr (2001), evolução é o conceito mais importante da Biologia. É aquele que dá sentido a diferentes aspectos e fenômenos biológicos, integrando-os no contexto histórico por causas naturais. Como um metafenômeno, é o próprio devir biológico. No entanto, mesmo aceito pela comunidade científica como a melhor explicação para a história da biodiversidade em nosso planeta, a ponto do geneticista Theodozius Dbzhansky (1900-1975) assinalar que "nada faz sentido em Biologia, a não ser à luz da evolução" (DOBZHANSKY, 1973), o tema tem sido omitido ou negligenciado em salas de aula por diversas 
razões (COBERN, 2007).

Alguns autores (e.g., SMITH, 2004; ALLMON, 2011) apontaram que as principais causas da dificuldade de assimilação de conceitos evolutivos por alunos do ensino médio são as seguintes:

i) conhecimento inadequado do conteúdo da Teoria de Evolução por Seleção Natural associado à falta de compreensão das evidências empíricas que a sustentam;

ii) treinamento deficiente em Filosofia da Ciência;

iii) influência religiosa fundamentalista subjacente;

iv) miscelânea de fatores psicológicos, políticos e sociais.

Desses, a falta de compreensão das evidências empíricas e o precário (ou nulo) treinamento de professores do ensino médio (e até mesmo universitários) em Filosofia da Ciência parece ser o que contribui de forma mais significativa para o fenômeno (ALLMON, 2011). Por causa disso, alunos recém-ingressos em universidades, mostram estranheza ou relutância quanto à assimilação de conceitos, pois não distinguem ciência de outras formas de saber (e.g., pseudociência, religião, metafísica). Em geral, o processo tem levado ao apartheid cognitivo (COBERN, 2007; HERMANN, 2012), ou seja, o desenvolvimento de um sistema ideológico autoimune com o objetivo de evitar que aquilo que se crê seja demonstrado falso por validação externa (SNELSON, 1992; PIEVANI, 2005). Com a relutância à avaliação crítica de novas ideias, evita-se o conflito existencial e a exclusão social. Desse modo, o indivíduo pode manter-se estável numa zona de conforto (BAUMAN, 2007). A motivação - de origem psicológica - corresponde a uma tendência humana pela busca de evidências que confirmem a todo custo ideias ou convicções pessoais e nunca para confrontálas (GASKIN, 2005).

Por razões que a Sociologia da Ciência tenta explicar, muitos cientistas também não escapam do vício, tornando-se resilientes, sustentando a todo custo suas hipóteses e teorias, apelando para explicações ad hoc (CHALMERS, 1993; PETERS, 1996; SOBER, 1993, 2008). Nesse contexto, podem distorcer fatos, forçar o enquadramento de dados na moldura teórica em que sentem mais conforto, elaborar análises equivocadas e até emitir interpretações inconsistentes. Por vezes, essa imunidade ideológica torna-se forte na comunidade científica, 
contrapondo-se à aplicação imparcial do critério de testabilidade, tão invocado na demarcação da ciência (FEYERABEND, 1989; PETERS, 1989; SOBER, 1993; SHERMAN, 2001; ASENSI-ARTIGA e PARRA-PUJANTE, 2002). Quando a observação é contaminada pela paixão, a testabilidade corre sério risco de ser substituída pela indesejável busca por confirmação e a ciência se voltar para a pseudociência. Particularmente, isso ocorre em áreas da pesquisa fortemente contaminadas por ideologias ou pela expressão de interesses conflitantes. Portanto, uma boa dose dos fundamentos da Filosofia da Ciência pode contribuir como antídoto.

Compreender como a investigação científica ocorre e os fatores que atuam por detrás dela permite a identificação das razões pelas quais certas ideias permanecem e outras são banidas do contexto científico.

Mesmo diante de cenário educacional desolador, assume-se que vale a pena o investimento contra a inércia intelectual (SAGAN, 2000) e a ciência aparece como "uma vela acesa no final do túnel". Com esse objetivo, projetamos introduzir, em três artigos complementares e sequenciais, alguns conceitos básicos da Filosofia da Ciência bem como ferramentas analíticas para a discussão de alguns temas centrais do evolucionismo contemporâneo. Nesse primeiro artigo, uma contextualização do problema é exposta em associação com fundamentos das ciências empíricas.

\section{DESENVOLVIMENTO}

\section{Zygmunt Bauman e o conhecimento nos "tempos líquidos"}

No iluminismo, em oposição à escolástica medieval, desenvolveu-se uma perspectiva filosófica voltada para a celebração dos valores humanos, endossando a liberdade de pensamento e expressão acima de tudo: o Humanismo Secular (ROHMANN, 2000). As ciências modernas assentaram seus alicerces ideológicos nessa nova perspectiva libertando-se, aos poucos, do domínio repressor e castrador da teologia medieval (LOSEE, 1979, MAGEE, 1998). Desde então, vários filósofos contribuíram direta ou indiretamente para o movimento (e.g., David Hume, Auguste Comte, Karl Popper, Bertrand Russell, Dan Dennet). 
$\mathrm{Na}$ perspectiva do humanismo secular, tendo a razão como referência, o intelectualismo passou a ser a melhor forma de avaliação, discussão e assimilação de ideias. Esse regime de iluminação recíproca, com a troca proveitosa de ideias, seria a própria raison d'etre da secularização do ensino e da ciência (HOSPERS, 1988; PIEVANI, 2005). A estratégia obteve certo sucesso e foi dominante durante boa parte da História Moderna, pelo menos, em ambiente acadêmico.

Na sociedade dita pós-moderna, aquela em que vivemos, na qual o consumismo, o isolamento e a exclusão tornaram-se aspectos marcantes (BAUMAN, 2007), a aquisição do conhecimento continua a ser tema de discussão. Assim, a perspectiva sociológica do polonês Zygmunt Bauman (1925-2017) revela-se bastante útil no esclarecimento do fenômeno nesses “tempos líquidos” (BAUMAN, 2007) (Fig. 1).

Atualmente, o conhecimento é acessível a todos, através de páginas da internet, redes sociais e aplicativos. Encontra-se em todo lugar para todo aquele que quiser obtê-lo. No entanto, na prática, aquele que melhor condiz com a realidade tornou-se muito restrito e modular (BAUMAN, 2007), localizado em sites específicos de ambiente acadêmico, com linguagem hermética, restrita a revistas especializadas. Em contexto científico, a situação se agrava por que o conhecimento científico cresce geometricamente, com a introdução de inúmeras metodologias, técnicas e conceitos, praticamente impossíveis de serem assimiladas pela maioria da população, com educação de base cada vez mais deficiente. É um cenário propício para a difusão do analfabetismo científico.

Figura 1. Sociólogo Zygmunt Bauman (1925-2017) .

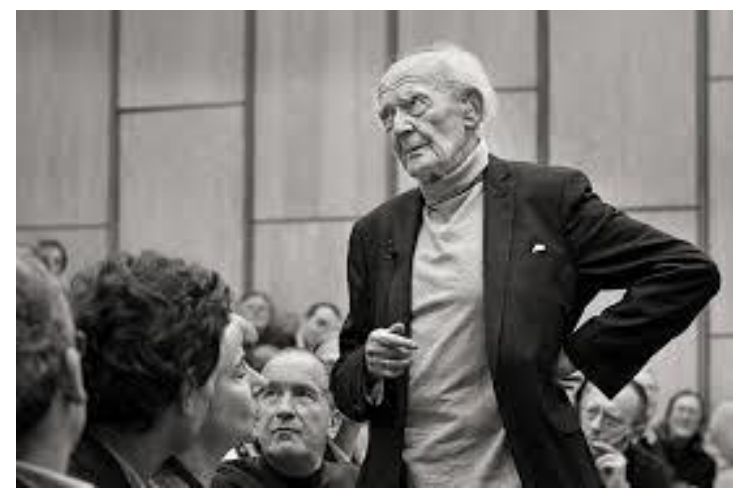

Fonte: http://obviousmag.org/archives/uploads/2013/12/01_bauman.jpg 
Nesse ambiente nebuloso e incerto, faz-se necessário o papel atuante e efetivo do professor como orientador, através da análise crítica e indicação de caminhos que conduzem a melhor correspondência com a realidade, desbancando e corrigindo a difusão de maus memes (FROTA-PESSOA, 2001).

Segundo Bauman (1992), a busca por segurança numa zona de conforto tem sido a maior das preocupações pessoais nesses "tempos líquidos", mais até do que a busca pela liberdade. Investir na aceitação social e, portanto, na própria sobrevivência tem sido a estratégia usada pelo indivíduo para se libertar do medo. A troca de ideias - intelectualismo stricto sensu - passou a soar como algo ameaçador porque pode levar o indivíduo a uma exposição excessiva, tornando-o altamente vulnerável à crítica rigorosa e à própria exclusão social. Logo, o conhecimento acrítico - ordinário, imediatista e técnico -, consolidou-se cada vez mais como aquele de preferência popular, em detrimento do reflexivo e crítico. E a repetição desenfreada de memes revelou-se como a estratégia mais usada no convencimento das pessoas, bem mais que o diálogo promovido pela razão.

Bauman (2007) apontou que o conhecimento na sociedade pós-moderna basicamente alcançou a condição de "fast-food", tornando-se fugaz, digerível e descartável. Tudo aparenta mudar rapidamente até evanescer. Ainda quando o conhecimento está prestes a ser assimilado, algo de novo surge e aquele antigo torna-se imediatamente substituído, assumido como obsoleto ou simplesmente descartado. Assim, nenhuma estimativa ou solução pode ser considerada conclusiva ou de base sólida. E a imensa quantidade de variáveis atuantes no sistema contribui como fator decisivo e desencorajador na tomada de qualquer atitude audaciosa.

Nesse cenário desolador, aprender coisas novas, além daquelas do senso-comum ou daquelas dogmatizadas por grupos sociais, passou a ser uma atividade tediosa, chata e, para muitas pessoas, uma perda de tempo (MEDAWAR, 1969). Em síntese, notadamente há restrita abertura para questões filosóficas e históricas nos "tempos líquidos". No ambiente acadêmico universitário, isso se reflete na maior procura dos alunos pelas ciências do "como?" em detrimento daquelas do "por que?". As do "como?" estão voltadas para as aplicações do conhecimento enquanto que as do "por que?", para suas implicações.

Segundo Bauman (2007), livrar-se de coisas é um processo mais vantajoso do que adquiri-las. Como no caso da Rainha de Copas exposto por Lewis Carroll (1832-1898) em Alice 
no País das Maravilhas (1865) e aplicada à sociedade: só resta correr com todas as forças para permanecer no mesmo lugar. E, efetivamente, o que se vê é o investimento canalizado na manutenção da zona de conforto.

Por esses motivos, a aceitação do communis opinio tem sido a estratégia pela qual o indivíduo busca obter posicionamento a respeito do mundo. E aquela opinião grupal, por imposição de autoridade, tem prevalecido como sendo a verdadeira. É a ditadura do sensocomum. Em sociedades com sintomas de grave disfunção social, em que cultura e educação funcionam precariamente e o estado se afasta de seus compromissos básicos com o cidadão comum, o processo atua com a pá de cal, reduzindo o indivíduo a uma inócua e apática parte do todo (STERELNY e GRIFFITHS, 1999). Na falta de assistencialismo efetivo por parte do Estado, o indivíduo tende a buscar apoio fora da realidade objetiva, apegando-se ao irracional ou ao imaginário como placebo ou esteio psicológico (BAGNASCO et al., 2010).

Assim, o ensino de evolução, como tantos outros, tem sofrido restrições nesses "tempos líquidos", indicando mudanças de estratégias. Cobern (2007) afirma que, ao contrário de tentar impor em salas de aula conceitos evolutivos, os professores deveriam expor Evolução como a explicação mais plausível para a história da biodiversidade em nosso planeta, criando estratégias para instalação de um ambiente propício ao diálogo. Assim, conceitos seriam melhor introduzidos e discutidos. Sua proposta, dita construtivista cultural, leva em consideração o contexto social. A tática envolve buscar ingredientes para que Evolução tenha, aos poucos, aceitação num meio cultural adverso, em que é praticamente destituída de significado. Isso requer a apresentação adequada das evidências e dos elementos que sustentam a teoria. Se Evolução é a maneira pela qual os cientistas explicam vários fenômenos atuais e passados, é necessário conhecer as ferramentas que os levaram a acreditar nessa proposta (CHALMERS, 1993; COOPER, 2001; MAYR, 2005; ELDREDGE, 1995). A adoção de um método dialético (socrático) - com perguntas incisivas e respostas arrojadas nesse diálogo aluno-professor -, pode ser também um caminho proveitoso (ALVES, 2003). Evidentemente, um arcabouço filosófico e científico deve ser introduzido, de modo que ciência e outras formas de obtenção de conhecimento possam ser comparadas e seus métodos criticamente avaliados. 


\section{Filosofia da ciência como a luz no final do túnel}

O confronto entre as ideias criacionistas (sustentadas pela fé) e evolucionistas (sustentadas por razão e evidências positivas) são raras na sociedade brasileira e quando ocorrem, são menos acrimoniosas que América do Norte. Porém, inevitavelmente, a influência ideológica subjacente se reflete no conteúdo oferecido pelos professores em sala de aula, de forma explícita ou velada (COBERN, 2007; ROSENBERG e McSHEA, 2008).

Apesar de grandes líderes religiosos (e.g., papas João Paulo II e Francisco I) não reconhecerem qualquer conflito entre ciência e religião, uma vez que objetivos e paradigmas são completamente diferentes, o mesmo não ocorre com a maioria da população que encara com desconfiança ideias adversas ou estranhas à situação vigente (AYALA, 2006).

O conflito é minimizado em países em que a educação básica é de melhor qualidade, a desigualdade social é menor e a liberdade de pensamento e expressão predomina, como no caso dos países do norte da Europa. Porém, em países emergentes, onde a educação de base é precária e a disfunção social evidente, a controvérsia tem levado a uma batalha no campo político-ideológico, com acúmulo de equívocos e difusão de informações distorcidas por todos os lados. Evidentemente, somente em regimes democráticos, a Filosofia da Ciência poderia funcionar como mediadora eficiente no debate (SAGAN, 2000).

Uma compreensão de como a investigação científica opera permite identificar problemas e encaminhar estratégias de ensino. Assim, conceitos evolutivos poderiam ser entendidos, conhecidos e melhor assimilados. Para tanto, uma breve exploração da epopeia da busca pelo conhecimento torna-se útil no encaminhamento do assunto.

Arendt (1978) sustenta que a razão é a diferença fundamental entre entender e conhecer. $O$ entendimento é importante para o conhecimento, mas não é o suficiente. Ayala (2006) afirma que conhecimento é o processo de pensamento em que se alcança a compreensão conceitual, a assimilação de um conceito. É a simples apropriação do objeto pelo indivíduo.

Para Platão (tomado de Parmênides; $c f$. TARNAS, 2001), haveria uma distinção entre de jure conhecimento (i.e., erudito, correto)-episteme-e aquele popular, equivalente a uma simples opinião (i.e., doxa). Livrar-se de doxa e concentrar-se em episteme, seria a nobre tarefa do pensador. $\mathrm{O}$ conhecimento legítimo a ser alcançado, segundo ele, estaria condicionado a isso. 
Laudan (1983) contesta o argumento e estende seu ponto de vista a ponto de afirmar que não há qualquer distinção entre ciência e outras formas do conhecimento.

Por objeto apropriado entende-se qualquer entidade, fenômeno, fato ou coisa a partir da qual é possível abstrair impressões particulares (AQUINO et al., 2011). Como resultado, a aquisição do conhecimento leva a se acreditar que é genuíno ou válido aquilo que se compreendeu. Daí a proliferação de posturas ideológicas e comportamentais engessadas ou incorruptíveis de indivíduos na sociedade. Porém, por se acreditar de forma diferenciada, conceitos podem fazer sentido e, portanto, serem mais acreditáveis para certas pessoas do que para outras. Dessa forma, é possível compará-los e analisá-los.

A forma mais elementar de conhecimento é o senso-comum (i.e., empírico puro), aquele baseado na experiência da vida cotidiana. Por tentativa e erro, condições disponíveis são selecionadas visando o domínio do objeto de interesse. Mas, por definição, esse tipo de conhecimento é superficial, passional, subjetivo, assistemático e acrítico (LAKATOS e MARCONI, 2001).

No âmbito neurofisiológico, os nossos sentidos possuem valor prático, mas não cognitivo. Há uma assimetria entre a causa de um fenômeno e seu efeito (i.e., percepção).

O cérebro interpreta informações derivadas de órgãos sensoriais e constrói um modelo mental de mundo (DENNET, 2011). Desse derivam termos (unidades linguísticas) e conceitos (aspectos da realidade objetiva) (BUNGE, 1985). Como resultado, surgiu a linguagem verbal-um complexo repertório simbólico que garante a propagação de conhecimento entre as pessoas (PINKER, 1998). Devido a isso, unidades de transmissão cultural-memes-se espalharam e direcionaram a evolução sociocultural (DAWKINS, 1976; DENNET, 2011).

David Hume (1711-1776), filósofo escocês, na sua tentativa de elucidar a natureza humana através de método instrumental (tal qual fora utilizado por Isaac Newton, na Física) para explicar o funcionamento da mente humana, explorou o entendimento e a sensibilidade. E concluiu que a fonte de todo processo cognitivo está na experiência do dia-a-dia, no empirismo. Para ele, todo conhecimento provem dos sentidos, sendo as ideias o resultado da percepção dos fatos que nos chegam ao cérebro através das sensações. Com isso, constrói-se a consciência, o ponto seguro da edificação do conhecimento. E aquilo que consideramos certeza trata-se de uma mera questão de probabilidade. 
É fato que, desde os primórdios da história da humanidade, o homem se preocupou com a obtenção de certezas quanto à apropriação de objetos do mundo físico buscando controlá-lo através de explicações concisas, coerentes e claras (SHERMER, 2011). Nesse contexto, um dos maiores avanços foi a passagem da simples crença individual para aquela socialmente legitimada.

Mas, havendo tantas crenças, como saber quais são as verdadeiras? Então, ao longo da história da humanidade, diferentes critérios foram empregados nessa avaliação. E diversas formas do saber assim se revelaram: empírica, técnica, artística, místico-religiosa, filosófica e científica (D'ONOFRIO, 1999). Cada uma com seus critérios próprios de julgamento quanto à eficácia ou veracidade (HOSPERS, 1988).

No mundo antigo, particularmente entre os gregos, o conhecimento era encarado como uma contemplação da realidade na condição em que algo sendo permanente, permite a revelação da sua verdade. Admitia-se que poderia ser obtido através da observação direta, que as coisas eram como se apresentam, tal como são percebidas pelos nossos sentidos. Esse conhecimento era fundamentalmente dedutivo, sem espaço para experimentos ou induções.

$\mathrm{Na}$ Idade Média, a natureza passou a ser investigada intuitivamente como algo sagrado (THORNDIKE, 1923-58), mas, mesmo assim, ocorreram progressos lentos e permanentes na compreensão de fenômenos naturais e no uso de recursos naturais (NORDENSKIÖLD, 1936).

Em tempos modernos, os ideais de domínio, controle, manipulação e aplicabilidade passaram a ditar as regras, sob o risco de se tratar o homem não mais como um fim em si mesmo, mas como meio (OLIVA, 2012). Daí a necessidade de se recorrer, de vez em quando, à Ética como mediadora.

Dependendo do conhecimento, notam-se impedimentos quanto a sua aquisição numa sociedade (OLIVA, 2012). Entre eles, destacam-se: (a) o hábito de colocar o "carro na frente dos bois", ou seja, no caso da antecipação prevalecer sobre a observação; (b) interesses escusos fazendo com que preconceito se passe por conceito; (c) pensamento recorrente apelando para a tradição; (d) fascínio pela autoridade em detrimento do pensamento crítico; (e) "canto da sereia" da retórica à custa da demonstração lógica e da comprovação empírica; (f) a subordinação da razão à fé; (g) uso inadequado da linguagem.

A ciência foi praticamente a última forma do saber a surgir na história da humanidade 
e logo esteve acompanhada de seu "controle de qualidade" - a Filosofia da Ciência (=Metaciência) -, à própria reflexão sobre a atividade do cientista.

O conhecimento científico está vinculado a um conjunto de sinais materiais convencionais - signos - que pertencem a uma ou mais linguagens (i.e., instrumentos de comunicação). Esse conjunto de signos artificiais arbitrários portadores de ideias é a própria porta de acesso às linguagens que podem ser divididas em:

(a) Linguagem natural ou espontânea - como o Português, que possibilita circulação de conhecimento ordinário;

(b) Linguagem artificial - como a da própria ciência, com signos extraídos do sensocomum e acrescidos de signos próprios.

A ciência que lida com os signos é a chamada semiótica. Cabe ao filósofo da ciência lidar com a análise semiótica da linguagem científica, concentrando-se em três níveis teóricos (BUNGE, 1985; OLIVA, 2012):

(a) Sintaxe - forma do discurso ou estrutura dos conceitos, relacionando signos a termos, com pretensões cognitivas, com clareza e inteligibilidade;

(b) Semântica - conteúdo do discurso, associação entre ideias e coisas, intenção (=conotação) e referência (=denotação) dos conceitos, relacionando de maneira unívoca linguagem com realidade;

(c) Pragmática - extensão ou domínio de aplicabilidade do discurso, o seu uso no âmbito social.

Com base nisso, o filósofo da ciência determina como se dá a produção científica, de que forma as teorias são concebidas, avaliando as razões lógicas e evidências empíricas que justificam sua aceitação (ou rejeição).

Se o filósofo da ciência está comprometido com procedimentos lógicos que justificam o argumento científico, as entrelinhas ("making-off") de como causas psicossociais afetam a produção científica, com destaque para erros, equívocos, desvios, violações e adequações às condições socioculturais vigentes, estão a cargo da Sociologia da Ciência (HULL, 1987). Basicamente, essa metaciência se concentra ao nível da pragmática, mas juntando lados cognitivo e social, e reduzindo ciência a mais um fenômeno social, entre tantos outros. Lida, 
entre tantos aspectos, com fenômenos do tipo "Leito de Procusto" que, em termos de ambiente acadêmico, tornou-se sinônimo da submissão de docentes de talentos e histórias de vida diferentes (e.g., pesquisador ou professor) às mesmas condições de avaliação, maximizando competição e minimizando cooperação (OLIVA, 2012). Ou ainda, lida com as causas que levam determinados pesquisadores a produzir mais descendentes intelectuais que outros, adquirindo, com isso, maior poder e prestígio na própria comunidade acadêmica (HULL, 1987).

Na tentativa de responder perguntas básicas, em Filosofia da Ciência, distinguem-se as seguintes abordagens:

(a) Ontológica - Teoria do ser (=ente ou entidade) em geral. Lida com a realidade de objetos de estudo e conceitos relacionados. Ex.: espécie, nicho ecológico, área de endemismo. Que justificativas devem ser apresentadas para serem considerados representantes da realidade objetiva?

(b) Epistemológica - Teoria do conhecimento. Como se adquire conhecimento sobre o objeto de estudo em questão? Ex.: como obter conhecimento sobre o comportamento de uma ave? Qual o melhor protocolo?

Para o cientista, essas questões estão inclusas na maioria dos artigos científicos, particularmente na seção material e métodos. De praxe, os fatos (input, influxo) e os problemas são colocados na introdução. E o produto-conhecimento obtido (output, efluxo) sobre o objeto de estudo em questão pelo protocolo metodológico encaminhado-é dito conhecimento científico (GEWANDSZNAJDER, 1989; RUIZ e AYALA, 2000).

Ao contrário do filósofo, para quem nenhuma resposta é conclusiva em si dada certa questão, o cientista assume alguma veracidade alcançada pela qualidade e/ou quantidade das evidências. E suas consequências (i.e., deduções) atuam como base para formalizar novas hipóteses e prever novas situações. De preferência, uma formalização deve ser encaminhada. Em geral, corresponde à transformação das ideias numa linguagem de ciência formal (lógica ou matemática), com o uso de algoritmos e modelos. Assim, o conhecimento científico avança e o "castelo de areia" vai sendo construído passo a passo.

Ao supervisionar a atividade dos cientistas (HOSPERS, 1988; PIGLIUCCI e BOUDRY, 
2013), o filósofo da ciência ocupa-se com as seguintes questões:

(a) O que separa o conhecimento científico de outros rivais?

(b) Como se adquire conhecimento científico?

(c) Como ele avança?

(d) Como saber se o objeto de estudo cai dentro do contexto científico? Qual seu status ontológico?

Frota-Pessoa (2001) sustenta que tais questões são muito relevantes por que, na vida cotidiana, as pessoas estão submetidas a um "bombardeio" de informações diversas, com a imposição de "verdades". Ocorre um verdadeiro "vale-tudo" pela perpetuação e replicação de memes. Porém, infelizmente, há pouca preocupação pessoal na avaliação crítica da fonte de informação e a própria informação em si.

Em ambiente acadêmico, para que ocorra a aceitação de uma publicação numa revista científica de qualidade (daquelas preocupadas com Impact Factor - um índice de aceitação e credibilidade) nota-se um protocolo peer review que envolve submissão do draft (versão preliminar) a especialistas (referee) dispostos a fazer uma avaliação extremamente crítica do documento, apontando fragilidades e fazendo correções. É fato que as revistas científicas de referência disputam entre si o prestígio pela qualidade e veracidade das informações fornecidas. Aquelas, tais como Nature ou Science, pelo rigoroso controle de qualidade, aceitam, em geral, $10 \%$ dos trabalhos submetidos, conferindo status para quem conseguiu publicar nelas (BAGNASCO et al., 2010).

Por outro lado, é comum em jornais e revistas populares declarações do tipo: "os cientistas dizem que este ou aquele produto é o melhor (...)"; que "está provado pelos cientistas a existência disso ou daquilo (...)"; que "a ciência nunca saberá isto ou aquilo (...)". Em geral, uma generalização é invocada para se dar legitimidade ao argumento: os cientistas como um todo e a ciência em particular.

A impressão que se tem é a de que os cientistas, de fato, constituem um corpo homogêneo de conhecimento ou que os resultados obtidos por um deles são prontamente aceitos, de forma consensual, pelos demais. Na prática, isso não acontece. Há um salutar (mas, por vezes, acrimonioso) conflito de opiniões entre eles. Disputam o mérito do argumento que mais se aproxima da realidade objetiva assumida. Para o leigo, isso transmite sinal de fraqueza 
nos argumentos. Mas, pelo contrário, é exatamente aí que reside à força da investigação científica: o criticismo (BUNGE, 1985; GEWANDSZNAJDER, 1989; PETERS, 1989; RUIZ e AYALA, 2000; PEQUENO, 2012).

Em contraste com o cidadão comum, o cientista é movido por dúvida e curiosidade. Crê com base nas boas evidências disponíveis. Mas isso não é suficiente. Não bastar crer, deve demonstrar de forma convincente por que crê.

Nenhum testemunho individual é prova decisiva para se admitir algo como verdadeiro, pois cada um pode perceber equivocadamente um fenômeno, pode haver disfunção neurofisiológica, o ambiente social pode contribuir com indução (sugestão), o estado mental individual pode estar no limite da psicopatia etc. (MAGNANI, 2005; ELDREDGE, 1985). Uma boa razão ou justificativa deve ser fornecida para a crença assumida, com a exposição das evidências ou provas que a sustentam de modo que outro cientista possa avaliar sua veracidade através do confronto. Cabe ao defensor do argumento apresentar o ônus da prova. Essa possibilidade de contraprova ou contraexemplo é a validação externa, bastante negligenciada por religiosos e pseudocientistas.

O rigor científico - que nada mais é que ceticismo posto em prática - tem dado ótimos frutos, exaltando o conhecimento científico diante de outros rivais (SHERMER, 2011). Esse ceticismo é fruto da liberdade de pensamento e só prolifera em sociedades democráticas, pluralistas e tolerantes, em que o autoritarismo dá lugar à reflexão crítica (SMITH, 2004). Infelizmente, essas sociedades tão desejadas não são ubíquas.

Curiosamente, ao se trabalhar com a metodologia da investigação científica, deparase com o fato de que não há consenso na comunidade científica quanto à definição do que vem a ser ciência ou método científico (PETERS, 1989). No entanto, existem ingredientes básicos imprescindíveis para na sua caracterização que nos permitem diagnosticar, por uma combinação única de elementos, o que é científico, separando-o de outras formas do saber.

Segundo Shermer (2011), os ingredientes básicos do conhecimento científico são:

Autocorreção - a possibilidade de eliminação de erros ou revisão de conceitos. É uma medida do quanto a ciência é flexível, mesmo sendo resiliente. Com isso, ao contrário das ideologias ordinárias, torna-se aberta a novos significados e enfoques. A longevidade e permanência de um conceito científico é sintoma da sua capacidade de superar e assimilar os 
testes para os quais foi submetido. Assim, autocorreção é uma consequência lógica do intelectualismo, a prática da salutar troca de ideais.

Testabilidade - propriedade das hipóteses poderem ser confrontadas com contraexemplos. Resistindo ao teste, há aceitação da hipótese; caso contrário, é descartada (refutada). Para um conceito ser admitido e sedimentado como fato científico, deve ter sido submetido a todo tipo de "pente fino" e ter resistido às contraprovas.

Cabe aqui dizer que refutação não implica em dizer que uma hipótese é conclusivamente errada, mas sim que sob certas circunstâncias (e.g., instrumentos, protocolos, técnicas), simplesmente não se sustenta. Muitas vezes o cientista precisa aguardar novas técnicas, abordagens e instrumentos na reavaliação de antigas propostas, esquecidas ou descartadas. Como exemplo, pode-se citar as previsões (=predições) feitas pelo físico Albert Einstein, há cerca de 100 anos, sobre a existência de ondas gravitacionais. Só em passado recente foi possível confirmá-las através de tecnologias então indisponíveis na época em que a hipótese foi encaminhada (BUNGE, 1985).

Repetibilidade - no caso de um fenômeno se repetir, há possibilidade de se fazer predições a seu respeito. É possível observá-lo várias vezes mantendo sobre controle os parâmetros-chaves das hipóteses formuladas. Assim, ciência busca explicar padrões replicados, gerando-se uma expectativa de nova ocorrência. Aquelas ocorrências isoladas (i.e., padrões únicos ou singulares) são muito difíceis (por vezes, impossíveis) de serem estudadas. Podem ser imunes à própria investigação científica, não dando condições mínimas para validação externa. Trata-se de um dos maiores problemas na justificação das ciências históricas que, por definição, lidam com a reconstrução de fatos pretéritos.

Predição - é uma consequência lógica do raciocínio dedutivo (Fig. 2). Dadas certas premissas, aponta-se que algo deve ocorrer proibindo-se assim a alternativa. Em outras palavras: "se isso ocorre, então (...) aquilo outro não pode ocorrer simultaneamente". Em ciência, buscam-se sempre predições empíricas testáveis. Esse poder de predição é o grande diferencial da ciência, permitindo separação entre ciências mais ("hard") ou menos ("soft") maduras. Nas ciências históricas, predição é substituída pela retrodição - uma robusta hipótese (ou conjunto de hipóteses) formulada para a reconstrução do que aconteceu (padrão) em passado remoto. 
Figura 2. Representação esquemática de hipótese científica preditiva. Sob certas condições limites $\left(C_{1}, C_{2}, \ldots, C_{n}\right)$, a amplitude provável de valores $( \pm$ erro) de uma variável dependente ou resposta $(\mathrm{Y})$, dada a variável independente ou valor preditivo $(\mathrm{X}) \mathrm{e}$ algoritmo apropriado $(\mathrm{Y}=\mathrm{a}+\mathrm{bX} \pm$ erro).

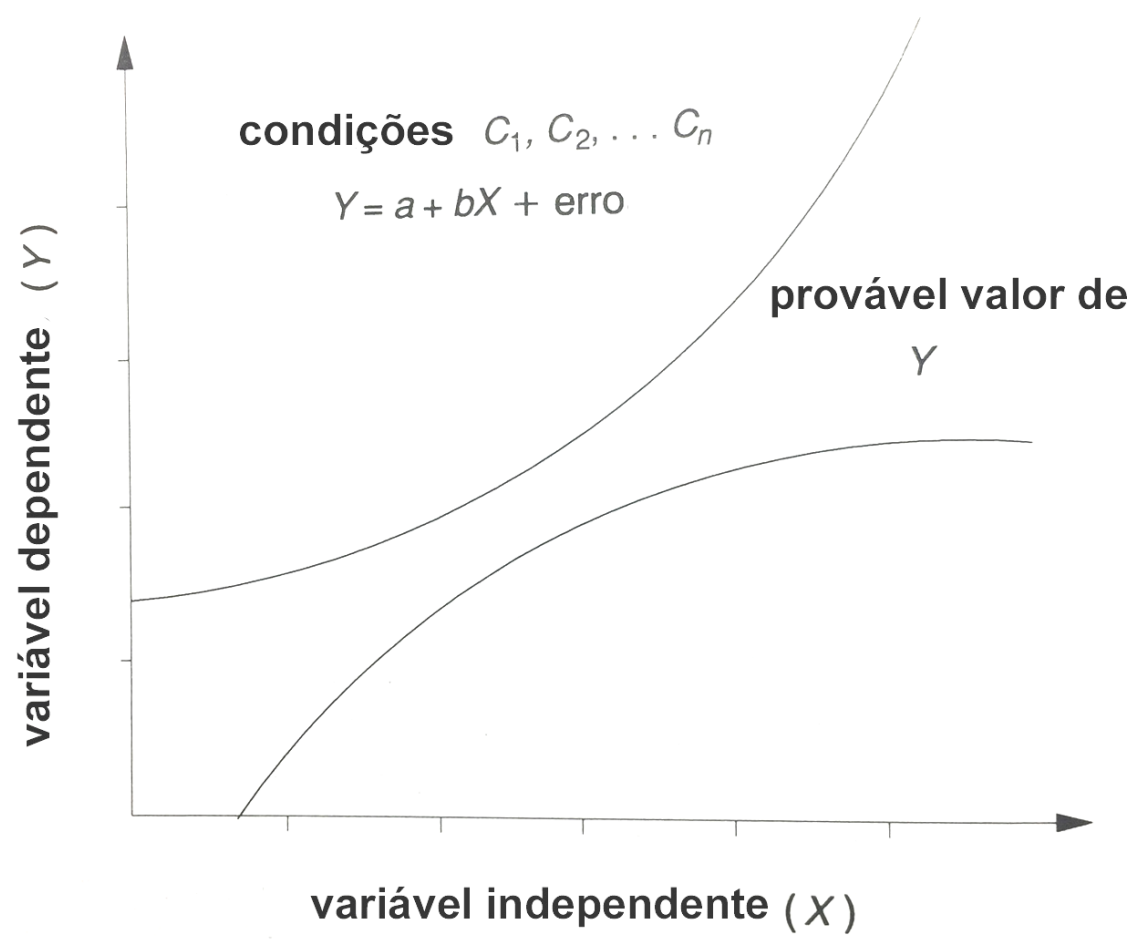

Fonte: Adaptado de PETERS (1989).

Evidência empírica positiva - é aquela acessível por observação, experimentação ou inferência. Considere a questão: como se sabe que artrópodes trilobitas existiram na Terra? A prova direta e objetiva é obtida de localidade fossilífera ou coleção paleontológica. Basta observar o material correspondente a um monte de restos de carapaças e apêndices petrificados ou impressões deixadas em rochas empilhadas dentro de uma gaveta de coleção e verificar que não pertence a qualquer grupo vivente. Logo, infere-se que um tipo de artrópode diferente existiu na Terra e que não alcançou o atual horizonte de tempo. Não é inseto, crustáceo ou aracnídeo, mesmo havendo compartilhamento de muitos atributos com eles.

Em 1771, o paleontólogo Johnann Ernst Walch (1725-1778) percebeu sua existência e erigiu o táxon Trilobita (Fig. 3). Encaminhou uma diagnose (i.e., conotação ou intenção do conceito) - uma combinação de atributos que permitem separar os trilobitas de outros invertebrados. Assim, como trilobita foi diagnosticado com um tipo de artrópode de corpo longitudinalmente trilobado (um lobo axial e dois laterais) e transversalmente dividido em 
escudo cefálico (zona anterior da carapaça, com os olhos e as peças bucais), tórax (zona intermediária, articulada, formada por um número variável de segmentos idênticos compondo módulos) e pigídio (escudo caudal). Por extensão, foi encaminhada uma definição (referência ou denotação) - a eleição das espécies que devem constar no grupo (HULL, 1974, 1987). Hoje se sabe que existiram ca. 17.000 espécies de trilobitas habitando ambientes marinhos, do Cambriano ao Permiano. A maioria tinha comprimento total de $3-10 \mathrm{~cm}$, mas em alguns casos atingiam mais de $70 \mathrm{~cm}$. Qualquer espécime coletado, satisfazendo as questões de conotação e denotação, corresponde a uma extensão ou exemplo de aplicabilidade do conceito.

Figura 3. Esquema da morfologia geral de um Trilobita. Por evidência empírica positiva é possível afirmar que os artrópodes trilobitas existiram em ambientes aquáticos do Paleozoico.

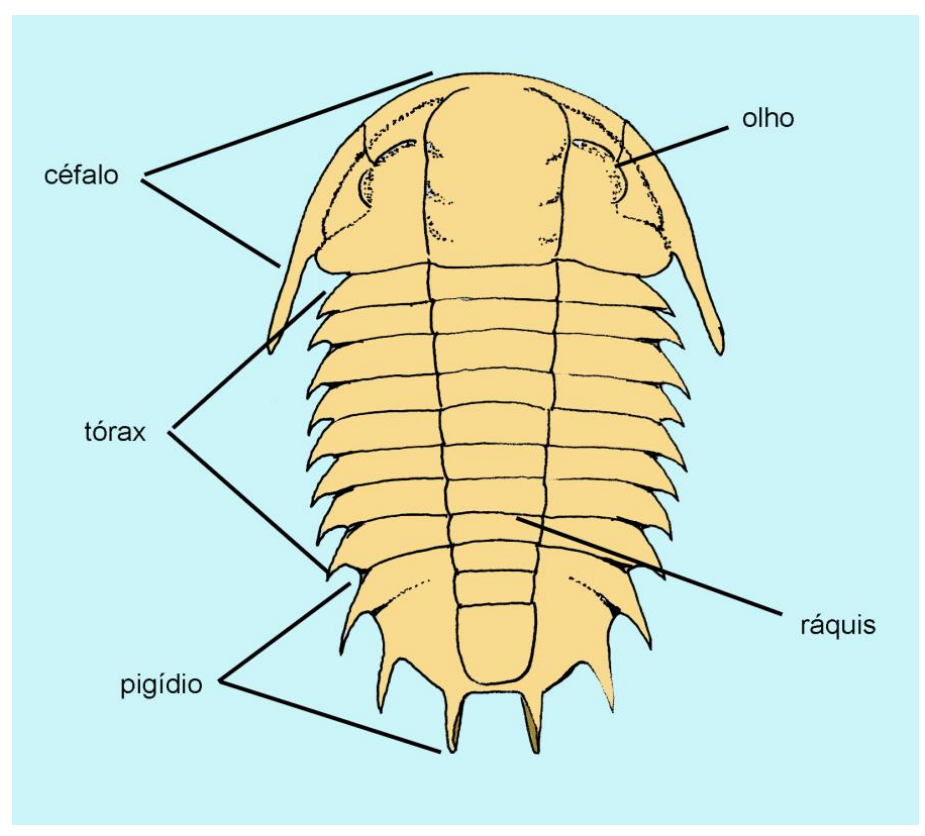

Fonte: Original.

Então, conclui-se que há muitas evidências empíricas positivas para se acreditar na realidade objetiva dos artrópodes trilobitas. Por seu status ontológico, trata-se bom objeto de estudo no âmbito científico. Pode-se gerar hipóteses e confrontar opiniões a respeito deles. 0 mesmo pode-se dizer quanto ao Tyrannosaurus rex ou ao primata hominídeo Australopithecus 
sediba. Porém, o mesmo não se pode dizer quanto a anjos, elfos, demônios, dragões, deuses e o saci-pererê.

Considere o caso do saci-pererê. No imaginário popular, é um ente fantástico, com aspecto de menino negro franzino, de uma só perna, com palma da mão furada, portador de carapuça vermelha e cachimbinho (CORSO, 2002). Habita matas e regiões agrestes. Para coletá-lo recomenda-se o uso de uma peneira de palha em cruz, que deve ser atirada sobre um redemoinho. Pode ser colocado no interior de uma garrafa cuja tampa de rolha deve ter uma cruz desenhada. Pronto e bom. Mas, por mais que pessoas tenham dito que o viram ou localizaram seu rastro, não há sequer um exemplar depositado em coleção, observação cofiável ou pista fidedigna. Mesmo havendo conotação e denotação, a extensão do conceito é um conjunto vazio. Portanto, não havendo o mínimo de evidência empírica positiva a favor, a aceitação da sua existência (realidade objetiva) é uma questão de crença, equívoco ou mau entendimento de algum fenômeno físico subjacente. Mas, para quem crê no simpático saci, basta dizer que o fato de outra pessoa nunca tê-lo visto não significa dizer que ele não existe. E isso basta. É o argumento em prol da evidência empírica negativa, tão usado e abusado pelos pseudocientistas.

Conclui-se que há conceitos que são imunes à investigação científica já que não se pode avaliar se correspondem ou não à realidade objetiva. Muitos não são consensuais ou não têm o mínimo de coerência racional que justifique uma investigação científica.

$\mathrm{Na}$ investigação científica, a escolha adequada do objeto de estudo é muito importante. A maioria das pessoas comumente começa uma discussão questionando: "há X, sim ou não?" Mas isso é feito a priori, antes mesmo de se perguntar "o que é X e o que estou querendo saber dele?" Deve-se atentar para o fato que o objeto X pode ser algo fora da realidade, existente só através da crença, fantasia ou superstição. Por isso, é preciso delimitar de forma adequada e explícita o objeto de estudo, contextualizá-lo, preferencialmente no tempo e no espaço, para se extrair dele o máximo possível de conhecimento.

Na escolha do objeto (e.g., SHERMER, 2011; BAGNASCO et al., 2010), recomenda-se a aplicação do imperativo categórico do psicólogo americano Ray Hyman (1928-), inspirado na perspectiva filosófica cética de David Hume: "não busque explicar algo até que você esteja seguro de que aquilo realmente existe". Como procurar o que não se sabe direito o que é e nem onde está? Isso, certamente, poupará tempo e esforço numa investigação científica. 
Em ciência, um objeto de estudo problemático é aquele que:

i) É ambíguo (i.e. aparece com vários sentidos);

ii) É uma simples definição (i.e., uma questão de convenção, arbitrariedade na associação significado-palavra), daí ser pouco informativo;

iii) Invoca respostas do tipo circunlóquio (e.g., "isto é porque é e pronto") ou por opiniões pessoais subjetivas (e.g., "minha intuição diz que..."; “eu acho que...");

iv) Leva à regressão infinita (i.e., definição seguida de definição, num contínuo sem fim) ou gera debates intermináveis, por que nenhuma observação específica constitui uma resposta conclusiva.

MEDAWAR (1969) destaca que ciência é a "arte daquilo que é solucionável". As perguntas devem ser formuladas de modo a gerar expectativa de resposta. Perguntas insolúveis ou intratáveis engessam o sistema (PETERS, 1989). Por exemplo: "por que há tantos tipos de animais?", "Por que existimos?" Nenhuma resposta é conclusiva e a questão pode se estender ad infinitum. Na investigação científica, perguntas que delimitam o objeto de estudo (e.g., quem? quanto? onde? quando?) são básicas (recuperam padrão) e constituem prérequisito para se chegar àquelas mais complexas (e muitas vezes, intratáveis) de cunho explicativo, que começam com por que? Outro problema é o uso de entidades metafísicas. Elas também travam o processo de investigação científica, pois não geram consequências testáveis. Devem ser eliminadas como explicação.

Ayala (2006) afirma que no criacionismo "científico" há referência direta ou indireta da intervenção de uma entidade divina que é associada ao Deus judaico-cristão. Assume-se $a$ priori que seja real e a causa daquilo que não se consegue explicar pela razão. Mas, não há qualquer justificativa (a não ser a própria crença) que justifique a entidade como sendo seja mais verdadeira que qualquer outra das várias religiões passadas e presentes. Nota-se uma verdadeira antinomia. É um erro fatal considerá-Lo consensual. Os gregos, por exemplo, entendiam que a natureza é tão diversa e contraditória que nunca poderia estar a cargo de uma única divindade. Deuses (e.g., Ganesha, Zeus, Odin, Jeová) possuem diferentes ontologias e histórias nas diferentes religiões (ELIADE e COULIANO, 1995; COTTERELL, 1997). Se a ideia de causa primordial para várias religiões é praticamente a mesma, os deuses invocados são 
bastante diferentes quanto a história e participação. Enfim, o conceito Deus é, ao mesmo tempo, polifilético (com múltiplas origens) e homoplástico (com funções análogas). Varia de acordo com a impressão pessoal e da sociedade em que está culturalmente inserido.

Longe da discussão quanto a sua existência (ou não), na investigação científica, o Deus judaico-cristão (assim como qualquer outro) não é um bom objeto de estudo científico porque: carece de conteúdo empírico. É imune a todo e qualquer tipo de teste do método científico. A sua autodefinição-ego sum qui sum-é por si uma tautologia (circunlóquio), fechada em si, inviabilizando qualquer possibilidade de geração de deduções (predições) testáveis. A sua aceitação é uma questão pessoal, de esteio psicológico, enfim, uma questão de fé.

E o que dizer sobre demonstrar a existência de um milagre? Por definição, se um milagre existe é porque não pode ser explicado cientificamente, ou seja, está além da capacidade ou possibilidade de demonstração. Milagre é aceito por evidência negativa ou simples raciocínio por exclusão (MAGNANI, 2005).

A diferença entre "ser" e "existir" é uma questão de demonstração, em função de provas. Qualquer pessoa pode dar uma boa descrição daquilo que pensa existir (e.g., sacipererê), mas, no contexto científico, deve fornecer prova da sua existência para que as pessoas possam verificar uma presença real. Sendo assim, o sobrenatural corresponde à incapacidade de se perceber algo através dos sentidos normais ou aquela condição em que a não há possibilidade de explicação racional conforme conhecimento científico e tecnológico correntes. Torna-se imune aos teste empírico e distante da realidade (SOBER, 2008).

Por tudo isso, conclui-se que ciência éagnóstica e não, ateia (i.e., descrente quanto a um deus pessoal) (SOBER, 2008). Por definição, ciência busca descrever somente o mundo natural (i.e., físico). Algo contribuiu para seu sucesso foi a adoção da postura de naturalismo metodológico, em que o sobrenatural ("conjunto vazio") é descartado como explicação (SOBER, 2008). Deu certo. Aquilo que não cai no escopo da investigação científica é dito metafísico, incluindo o caso do sobrenatural. Torna-se o objeto de estudo do filósofo.

Em contexto social, é fato que o suporte científico dá maior credibilidade a certas crenças ou ideologias quando essas disputam com outras rivais seu lugar no espaço. Torna-se bastante útil na luta de classes. Essa busca por justificativa na ciência é algo comumente visto na mídia jornalística atual ao mesmo tempo em que ela mesmo apela para a incapacidade da 
ciência de responder certas questões quando quer resguardar convicções de apelo popular e ganhar maior audiência.

Em função da abertura dada pela falta de compreensão (ou mesmo rejeição) de conceitos da Filosofia da Ciência, as pseudociências ocuparam um espaço significativo na sociedade e suas práticas costumam são endossadas pela mídia (ERNST, 2015).

Segundo Soubles et al. (2018), pseudociência pode ser definida como um conjunto de conhecimentos ou crenças que se apresentam como científicas ou imitam as formas e os vocábulos da ciência. Apesar do uso de jargão científico, não utiliza, a rigor, um metodo científico. Ao contrário, baseiam-se em suposições de "especialistas" que tentam corroborar intuitiva ou premeditadamente, a todo custo, uma crença de interesse. Entre as mais conhecidas pseudociências, destacam-se ufologia, parapsicologia, pseudo-história, teologia, pseudoarqueologia e astrologia. Acompanham terapias e práticas modernas, tais como florais de Bach, homeopatia, acumpuntura, cura quântica, reiki, meditação transcendental etc (ERNST, 2015).

Algumas propostas sem respaldo científico, usadas para sustentar certas ideologias, também se inserem no âmbito da pseudociência, como por exemplo: darwinismo social, “espiritismo científico" e "criacionismo científico” (e.g., intelligent design). Para surpresa geral, gozam da confiabilidade em vários setores da sociedade. E o pior, têm sido incluídas em ambientes políticos e até universitários.

Verdade absoluta só faz sentido em contexto religioso, pois aceita-se um dogma (verdade imposta), sem postura crítica. Daí, não fazer sentido uma classificação do criacionismo ou espiritismo científico como teorias científicas, pois aquilo que se acha verdadeiro é fixado a priori, mesmo havendo evidências suspeitas (ou nenhuma) a favor. Tudo aquilo que contradiz o "núcleo sólido" de verdades assumidas é imunizado (i.e., descartado ou "colocado debaixo do tapete"). Basta uma ocorrência favorável para se sustentar a crença, não importando a quantidade de insucessos acumulados.

Ernst (2015) afirmou: "quando a ciência é abusada, sequestrada ou distorcida para servir sistemas de crenças políticas ou ideológicas, padrões éticos escorregam. A pseudociência resultante é uma farsa perpetrada contra os fracos e os vulneráveis". 
Mesmo reconhecido o problema da penetração das pseudociências na sociedade, o ensino de ciências nas escolas não aplica tratamento rigoroso quanto a essas crenças, colocando-as à prova (FEYERABEND, 1989; SOUBLES et al., 2018). É recorrente a questão de falta de treinamento dos professores em Filosofia da Ciência.

Como se pode presumir, toda ciência deve ser, por definição, explícita; caso contrário, não é ciência. Daí não fazer sentido expressão do tipo "ciências ocultas". A linguagem também deve ser impecável, com margem mínima para interpretação ambígua.

Como já dito, a maioria da população busca certeza já que isso lhe dá conforto (BAUMAN, 1992, 2007). Manifesta horror à dúvida, pois a educação inadequada não lhes permite escolher criticamente uma entre várias propostas rivais. Preferem que lhes digam o que devem ou não fazer e pensar. Onde existe a disfunção social, aquele que diz ter o dom da verdade pode dizer para o resto o que se deve ou não fazer e, assim, obter o poder ou manterse nele. A estratégia tem dado certo ao longo da história da humanidade contribuindo para manter o povo sob controle. Somente nas sociedades em que a educação de qualidade se tornou a única forma de libertação e a ciência, um instrumento crítico de compreensão do mundo, o quadro mudou.

Diante disso, cabe uma reflexão. Como uma postura crítica inspirada pela ciência poderia ser útil no dia-a-dia, uma vez que o povo, em busca de conforto, crê em ideias ou conceitos que carecem de evidências ou provas?

Um conceito bastante difundido e combatido pela mídia é o preconceito. Deve-se dizer que não há quem não o tenha. Preconceitos (idola, de Francis Bacon) simplesmente induzem separações, dividindo classes de objetos. Podem ser entendidos como ideias ou posturas assumidas como verdadeiras, mesmo com evidencia inexistente ou duvidosa (ou tendenciosa). Lamentavelmente, para quem acredita cegamente, é inútil a exposição de evidência contrária porque dificilmente está propenso a discutir ou mudar de ideia. A sedimentação do conhecimento já foi feita de forma acrítica.

Essa atitude reticente pode parecer, à primeira vista, sintoma de firmeza ideológica ou indicação de caráter forte, porém a carência de posicionamento crítico na revisão de conceitos tem tornado as sociedades doentes, com a proliferação de posturas socialmente nocivas como fanatismo religioso, uniformidade de pensamento, discriminação, intolerância e 
manipulação de massa. Isso se traduz na apartheid cognitiva (i.e., imunização ideológica) disseminada na população.

Pode-se identificar na sociedade a diferença entre posturas ou atitudes mais ou menos críticas quanto à aquisição de conhecimento. De acordo com o senso crítico, podem ser antitéticas, como as seguintes:

\section{Postura não científica (i.e., anti-intelectual, irracional):}

“[...] Se todas as evidências do Universo se voltarem contra o Criacionismo serei o primeiro a admiti-las, mas continuarei sendo criacionista, porque é isso que a palavra de Deus parece indicar. Essa é a minha opinião." Kurt Patrick Wise (criacionista norte-americano) (cf. DAWKINS, 2007, p. 17).

O problema está na alimentação de um preconceito a despeito do quanto se demonstre que é falso. Continua-se a praticá-lo ou reverenciá-lo. Considere, por exemplo, o enunciado: mulheres são sempre menos capazes que os homens. Quanto a isto, não há qualquer evidência favorável. Nenhuma observação direta ou teste estatístico sustenta aquele enunciado. Agora, substitua a palavra mulher por negro, espírita ou ateu e homens, por brancos, cristãos ou religiosos e tem-se a propagação de novo preconceito infundado.

A postura científica revela-se aberta ao confronto e suscetível de mudança de opinião e perspectivas.

\section{Postura científica (i.e., intelectual, racional):}

"Se todas as evidências do universo se voltarem a favor do Criacionismo, serei o primeiro a admiti-las, e mudarei de opinião imediatamente. Na atual situação, porém, todas as evidências disponíveis (e há uma quantidade enorme delas) sustentam a evolução. É por este motivo e apenas por este motivo que defendo a evolução com uma paixão comparável à paixão daqueles que a atacam. Minha paixão se baseia em evidências. A deles (criacionistas), que ignora as evidências, é verdadeiramente fundamentalista." Richard Dawkins (biólogo evolucionista). [DAWKINS, 2007, pg. 18; itálico é nosso].

Não havendo o mínimo de evidências na sustentação de um argumento, é uma questão 
de probabilidade que o mesmo seja falso. Falsidade é, portanto, uma questão de probabilidade mínima.

\section{CONCLUSÕES}

Ao contrário de outras abordagens, aquela dita científica envolve a aplicação de criticismo e ceticismo na exploração de argumentos e fatos (SHERMER, 2010, SMITH, 2004). A postura é relevante uma vez que todo conceito, com o mínimo de realidade objetiva, é sujeito ao confronto diante de evidências. Assim, pode-se julgar se o meme é bom ou não (FROTAPESSOA, 2001).

Em sociedades onde a disfunção social é evidente e aguda, a noção de realidade tende a ser substituída por tolice ou alienação e, com isso, há o favorecimento de difusão de todo tipo de pseudociências e conceitos sem qualquer suporte racional. Assim, a manipulação popular por lideranças políticas que usam falácias ou meias-verdades como instrumento opressão torna-se mais fácil. Nesse triste cenário, o "canto da sereia" das pseudociências e do obscurantismo revela-se mais sedutor e ganha eco na sociedade, uma vez que o senso crítico (SMITH, 2004) da maioria da população torna-se nulo ou reprimido. Consequentemente, fatores sociais subjacentes, tais como a baixa qualidade do ensino e analfabetismo científico, contribuem para a nefasta retroalimentação. Diante disso, as ferramentas da Filosofia da Ciência e da Metodologia Científica constituem eficazes recursos em prol da liberdade de pensamento e expressão numa sociedade democrática.

\section{AGRADECIMENTOS}

Pela leitura crítica na fase de construção desse texto, com críticas e sugestões agradecemos ao Dr. Josimar Ribeiro de Almeida e Dra. Clarissa Canedo, do Instituto de Biologia Roberto Alcantara Gomes, da Universidade do Estado do Rio de Janeiro. Anja Cerri revisou os resumos. 


\section{REFERÊNCIAS}

ALLMON, W. Why Don't People Think Evolution Is True? Implications for Teaching In and Out of the Classroom. Evo. Edu. Outreach 4: 648-665, 2011.

ALVES, R. Filosofia da Ciência: introdução ao jogo e as suas regras. 7ª ed. São Paulo: Edições Loyola, 2003. AQUINO, A.R. de; G. de F. SEABRA; J.R. de ALMEIDA e M.G. RODRIGUES. Conhecimento, Gestão e Empreendedorismo. João Pessoa: UFPB, 2011.

ARENDT, H. The life of the mind. New York: Harcourt Brace Jovanovich, 1978.

ASENSI-ARTIGA, V; PARRA-PUJANTE, A. El método científico y la nueva filosofía de la ciência. Anales de Documentación, 4: 9-19, 2002.

AYALA, F. J. Darwin y el Diseño Inteligente: Creacionismo, Cristianismo y Evolución. Trad. Miguel Angel Coll. Madrid: Alianza Editorial, 2006.

BAGNASCO, S.; A. FERRERO; B. MAUTINO. Sulla scena del mistero: Guida scientifica all' indagine dei fenomeni inspiegabili. Milão: Sironi Editore, 2010.

BAUMAN, Z. Intimations of Postmodernity. London and New York: Routledge, 1992.

BAUMAN, Z. Vida líquida. Rio de Janeiro: Zahar, 2007.

BUNGE, M. La Investigación Científica. 2ª ed. Barcelona: Ariel, 1985.

CHALMERS, A. O que é Ciência afinal? São Paulo: Editora Brasiliense, 1993.

COBERN, W.W. Point: Belief, Understanding, and Teaching of Evolution. J. Res. Sci. Teach., 31(5): 583-590, 2007.

COOPER, R.A. The goal of evolution instruction: belief or literacy? Rep.Natl. Cent. Sci. Educ. 21(1-2):14-8, 2001.

CORSO, M. Monstruário - Inventário de entidades imaginárias e de mitos brasileiros. Porto Alegre: Tomo Editorial, 2002.

DAWKINS, R. 0 gene egoísta. Trad. Fernanda Ravagnani. São Paulo: Companhia das Letras, 1976.

DAWKINS, R. Deus, um delírio. São Paulo: Companhia das Letras, 2007.

DENNET, D. Quebrando o Encanto: A religião como fenômeno natural. Trad. Helena Londres. Rio de Janeiro: Editora Globo, 2011.

DOBZHANSKY, T. Nothing in biology makes sense except in the light of evolution. The Am. Biol. Teacher, 35: 125-129, 1973.

D’ONOFRIO, S. Metodologia do Trabalho Intelectual. São Paulo: Editora Atlas, 1999.

ELDREDGE, N. Unfinished Synthesis: Biological hierarchies and modern evolutionary thought. New York: Oxford University Press, 1985.

ELDREDGE, N. Reinventing Darwin: The great evolutionary debate. London: Orion Books, 1995.

ERNST, E. A Scientist in Wonderland. Exeter: Imprint Academic, 2015.

FEYERABEND, P. Contra o Método. Rio de Janeiro: Francisco Alves, 1989. 
FROTA-PESSOA, O. A guerra dos memes. Ciência e Ambiente, 12: 21-30, 2001.

GASKIN, J.C.A. Hume's philosophy of religion. New York: Barnes e Noble, 2005.

GEWANDSZNAJDER, F. O que é o método científico. São Paulo: Ed. Pioneira, 1989.

HERMANN, R.S. Cognitive apartheid: on the manner in which High School students understand Evolution without believing in Evolution. Evo. Edu Outreach, 5: 619-628, 2012.

HOSPERS, J. An Introduction to Philosophical Analysis. New Jersey: Prentice Hall, 1988.

HULL, D. Filosofia da Ciência Biológica. Trad. Eduardo de Almeida. Rio de Janeiro: Zahar Editores, 1974.

HULL, D. Science as a Process: An Evolutionary Account of the Social and Conceptual Development of Science. Chicago: Chicago University Press. 1987.

LAKATOS, E.M.; M.A. MARCONI. Fundamentos de metodologia científica. São Paulo: Editora Atlas, 2001.

LAUDAN, L. The Demise of the Demarcation Problem. p. 111-27. In: Robert S. Cohen and Larry Laudan (eds.) Physics, Philosophy, and Psychoanalysis, Dordrecht: D. Reide, 1983.

LOSEE, J. Introdução Histórica à Filosofia da Ciência. São Paulo: Editora Itatiaia e EDUSP, 1979.

MAGEE, B. The Story of Philosophy. New York: Dorling Kindersley, 1998.

MAGNANI, M. Spiegare i miracoli: interpretazione critica di prodigi e guarigioni miracolose. Bari: Edizioni Dedalo, 2005.

MAYR, E. What Evolution is. New York: Basic Books, 2001.

MAYR, E. Biologia, ciência única. Trad. M. Leite. São Paulo: Companhia das Letras, 2005.

MEDAWAR, P. The Art of Soluble. New York: Pelican Books, 1969.

NEIVA, E. O Racionalismo Crítico de Popper. Rio de Janeiro: Livraria Francisco Alves, 1998.

NORDENSKIÖLD, E. The History of Biology. New York: Tudor Publ., 1936.

OLIVA, A. Filosofia da Ciência. 3ª . Ed. Rio de Janeiro: Zahar, 2012.

PEQUENO, M. 10 Lições sobre Hume. Rio de Janeiro: Vozes, 2012.

PETERS, R. A Critique for Ecology. Cambridge: Cambridge University Press, 1989.

PETERS, E.K. No Stone Unturned: Reasoning about Rocks and Fossils. New York: W.H. Freeman, 1996.

PIEVANI, T. Introduzione alla Filosofia della Biologia. Roma: Editore Laterza, 2005.

PIGLIUCCI, M. Nonsense on stilts: how to tell science from bunk. Chicago: Chicago University press, 2013.

PIGLIUCCI, M.; M. BOUDRY (eds.). Philosophy of Pseudoscience. Chicago: Chicago University Press, 2013.

PINKER, S. Como a mente funciona. São Paulo: Companhia das Letras, 1998.

ROSENBERG, A.; McSHEA, D. Philosophy of Biology: A Contemporary Introduction. New York and London: Routledge, 2008.

RUIZ, R.; AYALA, F. J. El Método en las Ciencias: Epistemologia y Darwinismo. México: Fondo de Cultura 
Económica, 2000.

SAGAN, C. O Mundo Assombrado pelos Demônios. Trad. Rosaura Eichemberg. São Paulo: Companhia das Letras, 2000.

SHERMER, M. Por que as pessoas acreditam em coisas estranhas? São Paulo: JSN, 2011.

SMITH, P.J. Ceticismo. Rio de Janeiro: Jorge Zahar Editor, 2004.

SNELSON, J.S. The ideological immune system. Skept, 1(4): 44-55, 1992.

SOBER, E. Philosophy of Biology. Boulder, CO: Westview Press, 1993.

SOBER, E. Evidence and Evolution: The Logic behind the Science. Cambridge: Cambridge University Press, 2008.

SOUBLES, J.; R. PALOMAR; M.C. DOMINGUEZ. ¿En qué grado afectan las pseudociencias al profesorado? una mirada al pensamiento de los docentes de ciencias em formación. Mèthode Science Studies Journal, 96: 28-35, 2018.

STERELNY, K.; GRIFFITHS, P. Sex and Death: Na Introduction to Philosophy of Biology. Chicago and London: The University of Chicago Press, 1999.

TARNAS, R. A Epopeia do Pensamento Ocidental. 4ª .ed. Rio de Janeiro: Bertrand Russell, 2001.

THORNDIKE, L. A History of Magic and Experimental Science. New York: Columbia University Press, 1923-58

(cc) BY

Este trabalho está licenciado com uma Licença Creative Commons - Atribuição 4.0 Internacional. 